\title{
4
}

\section{OTC Derivatives and Counterparty Credit Risk Mitigation: The OIS Discounting Framework}

\section{Paola Leone, Massimo Proietti, Pasqualina Porretta, and Gianfranco A. Vento}

\section{Counterparty Credit Risk Reforms in Context}

Transactions in over-the-counter (OTC) derivatives by their very nature generate a particular form of credit risk, called counterparty risk, ${ }^{1}$ which should be properly managed in the current market. Since 2009 , dealers have come under increasing pressure to mitigate counterparty risk associated with OTC derivative transactions, especially

\footnotetext{
Although the paper has been prepared by authors jointly, Sects. 3, 3.1 and 5 have been written by Paola Leone, Sects. 3.1, 3.2 and 4 by Massimo Proietti, Sects. 1.2, 2 and 3 by Pasqualina Porretta and Sect. 1 by Gianfranco A.Vento.

${ }^{1}$ Unlike the credit risk generated by a loan, where the probability of loss is unilateral, insofar as it is held by the issuing bank, counterparty risk as a rule creates a risk of potential bilateral loss. In fact, the market value of the transaction can be positive or negative for both counterparties and the risk is manifested in the one where the value is positive in the case of insolvency (Basel 2). In addition, Basel 3 has predicted a specific capital requirement for the risk of changes in fair value of OTC derivative positions.
}

(C) The Editor(s) (if applicable) and The Author(s) 2016

S. Carbó Valverde et al. (eds.), Liquidity Risk, Effciency and New Bank Business Models, Palgrave Macmillan Studies in Banking and Financial Institutions, DOI 10.1007/978-3-319-30819-7_4 
after the collapse of Lehman and its default on OTC derivative counterparty obligations, and have moved towards the use of more stringent counterparty risk mitigation instruments/techniques. Consequently, in recent years a complex regulatory framework aimed at improving the functioning of the OTC derivatives market, reducing counterparty risk and enhancing transparency and protection for investors has been introduced and consolidated, obliging banks to comply with a series of requirements. In Europe these include: (a) financial markets (EMIR Regulation); (b) prudential supervision (Basel II and III); and (c) accounting (IFRS 13). These regulations will each be superimposed on the assets that suffer from counterparty risk, often creating organisational and procedural difficulties for the intermediary bank, as well as issues of measuring, collateralisation and, as will be seen throughout this paper, pricing.

Compliance with these regulatory frameworks, but above all the management implications and procedures resulting from them, require financial intermediaries that have extensive operations in these derivatives to carefully structure activities in counterparty risk management that can support risk management and finance in a more effective and integrated strategic and capital planning system. It is useful to analyse the main features of the regulatory framework since these reflect the operational realities of counterparty risk management .

\subsection{The EMIR Regulation}

EU Regulation 648/2012 (European Market Infrastructure Regulation (EMIR)), which came into force on 16 August 2012 and the subsequent delegated regulations, introduced stringent requirements relating to transactions in OTC derivatives. Its aims were to increase the transparency and resilience of the derivatives market, define a coherent regulatory framework for OTC derivative contracts, reduce interdependencies among intermediaries and ensure greater protection from market abuse. These requirements can be summarised in three main categories (or "pillars"): 
(a) Compensation from a central counterparty (CCP) or clearing house: "eligible" OTC derivatives must be cleared ${ }^{2}$ in CCPs, independent legal entities that stand between the parties to a derivative contract, activating structures of multilateral collateralisation. The $\mathrm{EMIR}^{3}$ framework establishes very stringent requirements for CCPs. In particular they must: (a) have sound corporate governance to guarantee transparency and to avoid potential conflicts of interest and appropriate systems and procedures, which will be subject to independent audits; (b) institute a risk management function and an audit committee; (c) mitigate all their exposure to collateral, highly liquid, and with a minimum credit and market risk (each subscriber to the CCP is therefore bound to pay the collateral to cover any failure of the other members); and (d) the meet the margin requirements, ${ }^{4}$ which must cover at least $99 \%$ of the frames over a set period of time if they are to be collected from clearing members. To be authorised to carry out these functions, the CCP needs a minimum share capital of EUR 5 million, to be used to cover any losses after the margins and the guarantee fee have been applied. The CCP must also acquire additional financial resources to cover potential losses that can exceed the margins and the guarantee fund in the event of default.

(b) Techniques for risk mitigation: OTC derivatives not compensated by a $\mathrm{CCP}$ are subject to procedures for mitigating the credit risk of the

\footnotetext{
${ }^{2}$ According to Article 4, Paragraph 13: the counterparties perform the compensation of the derivative contracts belonging to a class of OTC derivatives if these simultaneously satisfy two characteristics: (1) Their conclusion occurred in one of these ways: (a) Between two financial counterparties; (b) Between a financial counterparty and a non-financial counterparty; (c) Between two non-financial counterparties; (d) Between a financial counterparty or a non-financial one and a subject of a third country, which if located in Europe would be subject to the clearing obligation; (e) Between two subjects in one or more third countries, which if located in Europe would be subject to the clearing obligation. (2) There are entered into or novated: (a) starting from the effective date of the clearing (b) starting from the effective date of the clearing referred to in Article 5, paragraph 1, Regulation (EU) number 648/2012 - EMIR (European Market Infrastructure Regulation), http:// ec.europa.eu/finance/financial-markets/derivatives/index_en.htm.

${ }^{3}$ Regulation (EU) number 648/2012 - EMIR (European Market Infrastructure Regulation), http://ec.europa.eu/finance/financial-markets/derivatives/index_en.htm.

${ }^{4}$ To determine the value of the margins to be collected from clearing members, the central counterparties should use models and parameters that take into account the risk of the products cleared. These models are subject to validation by the supervisory authority.
} 
counterparty/operative, such as: (1) timely confirmation of the transactions concluded and the relevant contractual conditions; (2) compensation agreements and bilateral collateralisation through Credit Support Annex (CSA); ${ }^{5}$ (3) daily monitoring of the value of existing contracts; (4) periodic reconciliation of portfolios between the parties; (5) evaluation at least every six months (depending on the number of contracts) of the possibility of compressing the portfolio by combining multiple operations in a single trade or reducing the number of operations through a total or partial early closure; and (6) adoption of procedures for the prompt management of disputes. ${ }^{6}$

(c) Report to the trade repository: all derivatives (whether compensated or not) must, since 12 February 2014, be reported by financial and nonfinancial companies to a trade repository, that is a central repository authorised or recognised by the European Securities and Market Authority (ESMA) which is required to meet certain operational, registration and data management requirements. This reporting can also be delegated to external providers.

\subsection{Bilateral Collateralisation}

The EMIR requires careful collateral management, because it: (a) provides for the creation of new "systematic operators" (the CCP which will manage, control and mitigate the counterparty credit risk in OTC derivatives) that act as the clearing house in standardised futures markets; (b) prescribes the mandatory use of additional tools to mitigate risks; and (c) provides for bilateral collateralisation through a Credit Support Annex (CSA) with standards for margin collateral set by law for all OTC derivatives not eligible and not subject to central clearing. The CSA is a bilateral collateralisation agreement based on the payment of margin requirements: the two counterparties with OTC derivatives undertake to pay the amount of collateral (real guarantees) equal to the mark to market (MtM) of the derivatives, in order to cancel the net exposure in the case of default by either.

\footnotetext{
${ }^{5}$ Regulation (EU) number 648/2012 - EMIR (European Market Infrastructure Regulation). ${ }^{6}$ Official Journal of the European Union, Legislative Acts, EU Regulation number 648/2012 of the European Parliament and of the Council of 04 July 2012, Title II, Article 11, page 22.
} 
These agreements therefore presuppose exposure monitoring, that is the value of the transactions $(\mathrm{MtM})$, given the discounting of cash flows, the frequency of which is set by contract. The CSA determines the terms under which collateral must be posted as well as the eligible assets and currencies. In the case of insolvency of the counterparty an "early termination" occurs; the other party can use the collateral to cover the losses made and has the right to receive the costs of the substitution. ${ }^{7}$ The fundamental principle that governs the operation of the CSA provides for the identification of a maximum financial exposure (called threshold), representing the maximum permissible deviation between the value of the positions and the guarantee, above which there is the adjustment of the collateral. The deposit of a guarantee against the counterparty therefore occurs when the exposure of one towards the other exceeds the pre-defined threshold, beyond which the party with positive exposure is entitled to request the establishment of a real guarantee and therefore the payment of additional collateral. This must take place within the period of constitution of the guarantee (margin period), that is the maximum time allowed for the constitution of the guarantee once the threshold has been exceeded. The guarantees are represented by cash ( although high credit rating bonds can also generally be used), deposited in specific accounts payable to each counterparty, and the collateral is typically adjusted daily. Banks are therefore exchanging collateral on a daily basis since this method is now very common.

The amount of guarantees exchanged is determined by the daily variations in the market value of positions with a given counterparty market, clearly taking into account the amount of collateral already available. More specifically, when the value of the derivative instruments increases, generating a higher level of debt, the market counterparty integrates guarantees through an additional stream of money (called the delivery amount). Conversely, when the value of the current position decreases, the counterparty has the right to a refund of the excess guarantee. The call for collateral only occurs when the guarantee to be transferred is greater than the minimum amount established contractually, known as the minimum

\footnotetext{
${ }^{7}$ Represented by the mid-market value at the time of the default adjusted for the bid-offer spreads charged to the counterparty that has not failed which will have to pay in order to substitute the contract that has been terminated early.
} 
transfer amount (MTA), which is usually in excess of EUR 250,000. So if the $\mathrm{MtM}$ increases with a slight variation no exchange takes place. In the operational management of the CSA, the valuation of outstanding positions is made by the aggrieved party without prejudice to the debtor being able to initiate a process of contestation (called dispute resolution) in the case of disagreement with their financial evidence.

In the latter case the valuation of positions is entrusted to four leading market counterparties, and the two CSA counterparties accept without question the average of the four valuations. To simplify CSA operational management and to reduce the risk of disputes, it is possible to insert a further clause (called an alternative dispute) to limit the use of this process to cases where the value in dispute exceeds an amount established by contract (called the dispute resolution level).

Additional clauses can also be added, for example to cover undisputed evaluations and add a date representing the mean differential value.

This system of collateralisation generates significant effects in terms of business opportunities for the intermediary: value is produced by the reduction of the risks associated with financial operations, the increase in volumes and the execution of innovative transactions for purchases significantly higher than traditional credit management. If we add the fact that the proper management of volumes of collateral exchanged between counterparties also provides the opportunity to create additional revenues in the form of a spread, the inherent advantages of bilateral collateralisation immediately become apparent (Porretta et al. 2011).

\section{Counterparty Risk in the Capital Regulatory Framework (Basel II and III) and in the International Accounting Standard}

Under the prudential bank framework, intermediaries with assets that "suffer" counterparty risk will have to comply with the new Basel III requirements. In $2011^{8}$ the Basel Committee on Banking Supervision

\footnotetext{
${ }^{8}$ BCBS (2011), International regulatory framework for banks, http://www.bis.org/bcbs/basel3.htm.
} 
(BCBS) introduced new regulatory measures aimed at raising the capital resources to cover these exposures, reducing the procyclicality of supervisory rules and providing additional incentives to encourage settlement through CCPs for OTC derivatives contracts, thereby contributing to reduce systemic risk in the financial system. Among the main innovations concerning counterparty risk introduced by the framework of Basel III (not present in Basel II) are:

- Promotion of CCPs and the introduction of a specific treatment for exposure to these;

- Tightening of requirements relating to counterparty risk in different areas such as the treatment of the wrong-way risk, ${ }^{9}$ back-testing and stress testing ${ }^{10}$;

- A capital requirement to cover potential losses due to changes in market prices (risk of write-downs of the credit component, or credit valuation adjustment (CVA) due to the deterioration of the creditworthiness of the counterparty). The Basel II framework considered the counterparty credit risk (for which there is an ad hoc capital requirement), but not the CVA, which during the financial crisis has caused losses (produced by the simple deterioration of the creditworthiness of the counterparty) higher than those relating to cases of insolvency. The CVA is an adjustment of the value of the derivative according to its own variability and could be seen as a valuation allowance made against a loan portfolio. ${ }^{11}$ An important assumption in the CVA estimate is that the probability that the other party may be insolvent is independent of the exposure of the operator to that counterparty. Furthermore the CVA is based on a potential loss of credit, which occurs only if, at the time of default, the remaining cash flows have a positive value (only in this case is the CVA calculated).

\footnotetext{
${ }^{9}$ The so-called wrong-way risk, namely the increase in exposure when the credit quality of the counterparty decreases.

${ }^{10}$ The retrospective assessment of exposure to counterparty risk.

${ }^{11}$ Vecchiato W., Virguti E., Rischio di controparte, derivati e Credit Value Adjustment: strategie e metodi di gestione, Bancaria number 5/2013, page 49.
} 
Table 4.1 summarises the Capital Requirements Directive (CRD) IV, and provides a definition of credit valuation adjustment, ${ }^{12}$ its scope, its method of calculation and cases of exclusion from the CVA calculation.

The theme of the counterparty risk, in general, is also stated in the CRR and the same CRD IV in the different aspects of measurement, organisation and control (see Table 4.2).

The prudential supervision framework recognises central clearing and bilateral collateralisation and aims to reduce capital requirements even if with different entities.

Table 4.1 The CVA in CRD IV

\begin{tabular}{|c|c|}
\hline $\begin{array}{l}\text { Definition } \\
\text { (Article 381) }\end{array}$ & $\begin{array}{l}\text { Credit valuation adjustment (CVA) means an adjustment to } \\
\text { the mid-term review of the market portfolio of transactions } \\
\text { with the counterparty. This adjustment reflects the current } \\
\text { market value risk of the counterparty to the institution, but } \\
\text { does not reflect the current market value of the credit risk } \\
\text { of the institution to the counterparty. }\end{array}$ \\
\hline $\begin{array}{l}\text { Scope of } \\
\text { application } \\
\text { (Article 382) }\end{array}$ & $\begin{array}{l}\text { OTC derivatives are excluded, therefore, SFT transactions and } \\
\text { operations with long-term transactions, transactions with } \\
\text { an eligible counterparty, transactions between a customer } \\
\text { and a direct participant, transactions with counterparties in } \\
\text { Article } 1,2 \text { and } 3 \text { of Regulation (EU) number } 648 / 2012 \\
\text { (EMIR). }\end{array}$ \\
\hline $\begin{array}{l}\text { Method of } \\
\text { calculation } \\
\text { (Articles } \\
\text { 383-384) }\end{array}$ & $\begin{array}{l}\text { Advanced method (used by brokers who are authorised to } \\
\text { use the internal models approach like EPE) and } \\
\text { standardised approach. }\end{array}$ \\
\hline $\begin{array}{l}\text { Cases of } \\
\text { exclusion } \\
\text { (Article 385) }\end{array}$ & $\begin{array}{l}\text { For the instruments referred to in Article } 382 \text { and with the } \\
\text { appropriate authority, institutions using the original } \\
\text { exposure method may apply a multiplication factor of } 10 \text { to } \\
\text { the values of the risk-weighted exposure, thus avoiding the } \\
\text { need to calculate the CVA. }\end{array}$ \\
\hline
\end{tabular}

Source: Authors' elaboration from Official Journal of the European Union, Directive 2013/36/EU, of the European Parliament and the Council of 26 June 2013

\footnotetext{
${ }^{12}$ Official Journal of the European Union, Directive 2013/36/EU of the European Parliament and the Council of 26 June 2013, Title IV, Articles 381 to 385, pages 224-228.
} 
Table 4.2 Other legal sources of counterparty risk
Legal
sources References
CRR Analyses the counterparty risk in Chapter 6, Section 1, Articles
271-294a
Article 272 provides a definition of counterparty risk.
Article 273 specifies the method of determining the exposure value (computation methods as defined in Sections 3,4, 5 and 6).
Section $3^{\text {b }}$ regulates the "market value method", according to which the potential credit exposure is determined by multiplying the notional amounts or underlying values by the percentages indicated in the table.
Section $4^{c}$ regulates the "original exposure method", according to which the exposure value is the notional value multiplied by the percentages included in the reference table.
Section $5^{\mathrm{d}}$ regulates the "standard approach", which may only be used for OTC derivatives and for long-term transactions. The calculation of the exposure must be done separately for each set of activities subject to compensation according to a specified formula.
Section $6^{\mathrm{e}}$ regulates the "internal models approach". Article 283 specifies that use of this model is subject to the permission of the supervisory authority. If this is not given, the market value method and the standardised method must be used.
Stress tests, which are also regulated, apply where possible events or future changes in economic conditions are identified that could have unfavourable effects on the exposures; these assess the capacity of the intermediary to deal with these circumstances. The stress tests must be reported periodically at least on a quarterly basis.

CRD IV ${ }^{f}$ Includes:

Article $75^{9}$ : the corporate bodies of banks must approve strategies and policies for risk taking, properly assess the risks and establish an internal Risk Committee.

Article $79^{\text {h }}$ letter b) recommends the establishment by institutions of internal methods to evaluate counterparty risk.

Article 381 to Article 385 regulates the valuation adjustment risk (CVA). This section, together with the contents of the Basel III document, is intended to clarify the meaning and the use of the added capital requirement foreseen by the rules for the counterparty risk.

Source: Authors' elaboration from Regulation (EU) No 575/2013 of the European Parliament and of the Council of 26 June 2013 on prudential requirements for credit institutions and investment firms and amending Regulation (EU) No $648 / 2012$ 
Table 4.2 (continued)

albid, p. 167

blbid, p. 171

clbid, p. 171

dlbid, p. 171

elbid, p. 175

EU Regulation number 575/2013 and Bank of Italy circular number 285/2013 recognise the bilateral collateralisation agreements (obligatory for EMIR), including counterparty and credit risk mitigation (CMR) techniques, which lead to savings in terms of lower capital absorption, provided certain legal and organisational requirements are met. ${ }^{13}$ In particular, the operating assumption of the exchange of real financial guarantees is bilateral compensation under which mutual claims and liabilities between the counterparties are automatically amalgamated in order to establish a single net balance.

It should be remembered that even the changes introduced by Basel III provide a number of incentives for banks to make use, for OTC derivatives, of CCPs with strong capital and operational standards and equipped with an airlock able to protect participants against counterparty risk. Derivatives that are traded through central clearing systems are in fact not covered in the calculation of the CVA capital requirement.

\footnotetext{
${ }^{13}$ In order to approve bilateral compensation agreements to reduce the exposure value (pursuant to Article 296 and 297 of CRR), the bank must meet the following requirements:

- Stipulate with the counterparty a compensation agreement contract that creates a single legal obligation, corresponding to the net balance of all included transactions;

- Obtain legal opinions confirming that, in the event of a legal challenge, the judicial and administrative authorities would confirm the effects of the agreements;

- Establish procedures intended to ensure that the legal validity of the compensation is under review in light of possible changes in the relevant laws;

- Retain in its records all required documentation relating to the contractual netting;

- Consider the effects of compensation agreements for the purpose of calculating overall exposure to each counterparty and manage counterparty risks on this basis;

- Proceed, with respect to each party, to the aggregation of single transactions subject to compensation, in order to obtain legally significant exposure to this counterparty. This aggregate must be considered in the management processes of credit limits and capital allocation;

- Fulfil the information requirements of eligibility established by CRR with regard to disclosure, under Part Eight, Title II of CRR.
} 
With these measures, the regulator has undoubtedly sought to encourage bank intermediaries to focus trading of derivatives offset centrally rather than those not compensated through a CCP.

The new international accounting standards, in particular IFRS13, "Valuation of Financial Instruments" (which applies for financial years beginning from 1 January 2013), concerning the determination of the fair value of OTC derivatives, confirm the obligation to apply the credit valuation adjustment (CVA) related to counterparty risk for balance-sheet assets and introduces the debit valuation adjustment (DVA), or fair value adjustment, for financial liabilities, reflecting their risk of default on these instruments. The inclusion of CVA or DVA in determining the fair value of derivative assets or liabilities on the balance sheet brings about a reduction or increase in the mark to model calculated on the basis of risk-free rates.

In the historical probability of default approach, CVA/DVA is defined as:

$$
C V A(D V A)=E A D \times P D \times L G D
$$

where EAD (exposure at default) is exposure to the valuation date equal to the fair value of the derivative determined from the risk-free rate, $\mathrm{PD}$ is the cumulative default probability at the measurement date associated with the duration of the derivative, estimated according to the rating of the issuer, estimated on the bases of the rating of the issuer, ${ }^{14}$ and LGD (loss given default) is the loss in case of insolvency.

Therefore, the fair value of the derivative adjusted for counterparty risk is determined as follows:

$$
F V=M T M-C V A \times D V A
$$

As noted previously, since the adjustment for the counterparty risk involved intervenes only in the calculation of the fair value of the derivative, there could be a partial hedge ineffectiveness, especially if structured prior to the adoption of IFRS 13. In order to avoid this, counterparties may con-

\footnotetext{
${ }^{14} \mathrm{Often}$ reference is made to the probability of default of the issuers published by the external rating agencies.
} 
tinue to use risk-free discount curves, but only if adequately protected from counterparty risk, in line with the clearing and risk mitigation obligations introduced by EMIR for all unlisted derivatives entered into or novated with effect from 16 August 2012, the date of entry into force of the regulation. In particular, the intermediary bank does not make any adjustments in the fair value of the CVA and DVA derivatives if, at the date of closure of the balance sheet, there are agreements in collateralisation of derivative positions with features that ensure coverage of "effective" counterparty risk, namely:

- bilateral exchange of collateral on a daily or at least mid-week basis;

- collateral in the form of cash or government bonds of high liquidity and credit quality, subject to appropriate prudential spread;

- the absence of a fair value threshold for the derivative below which an exchange warranty is not envisaged, or the setting of such a threshold at an appropriate level to enable an effective and significant mitigation of counterparty credit risk;

- a minimum transfer amount (MTA), below which adjustment of the collateralisation of the positions does not take place, identified by contract at a level which allows a substantial mitigation of counterparty risk.

The use of collateralisation agreements, even for the application of the regulations, has led to a major change in the process of determining the fair value of the derivative; the use of discount-curve cash flows relating to the derivative which take account of immunisation of the counterparty risk is, therefore, also the return on collateral. The financial industry has configured a new valuation framework which has radically altered the pricing stage of counterparty risk management. This is the overnight index swap (OIS) discounting framework relating to new methods of discount cash flows from OTC derivatives.

\section{OIS Discounting: Theoretical and Operational Implications}

International financial crises create a great change in the pricing of derivatives, in particular in how (contingent) cash flows should be discounted to define the mark to market of financial assets. Historically, derivatives 
transactions were 'discounted', or valued using discount rates derived from Libor/Euribor rates. As cash generally cannot be invested at Libor/ Euribor, this is probably not the right discounting curve, even for Libor derivatives. During the most recent crisis practitioners witnessed a tremendous increase in basis swap spreads, implying a divergence from implied rates and traded rates in interest rate markets (for example, Euribor 6M against Euribor $3 \mathrm{M}$ ). The reasons for this situation are the existence of a significant counterparty risk that - if not mitigated - is higher and the frequency of the payments associated with a particular financial instrument. Consequently, the interest rate swap (IRS) rates quoted against Euribor in the short term (for example, Euribor 3M) have become lower than the IRS against Euribor with a higher maturity (for example, Euribor 6M).

The emergence of counterparty risk in the financial markets and on the books of financial intermediaries has made mitigation techniques necessary (even mandatory, as noted above); specifically, the presence of derivative transactions backed by collateral - to mitigate the risk profile-has become best market practice. The collateralisation of the counterparty risk implies that the MtM on derivatives takes into account the remuneration of the collateral itself through the application of appropriate discount curves.

In the early year of crises this question does not seem to have received much attention in the literature and in the financial industry, although in finance different discounting curves are usually used either to price different financial instruments or to price the same instruments issued by different obligors. This is incorrect because different issuers have different counterparty/credit risks which need to be considered in the discount rate. Since the introduction of the regulatory frameworks discussed above, the MtM of a derivative transaction between two counterparties is typically collateralised; this means that if counterparties $A$ and Benter into a derivative transaction and the trade has a positive $\mathrm{MtM}$ in favour of $A$, then $B$ will be required to post collateral up to the value of this mark to market. The primary objective of collateral agreements is to mitigate counterparty credit risk; that is, to protect $A$ from the event where $B$ is unable to meet their commitments under the transaction.

As markets have evolved, with derivatives generally being collateralised, it has been recognised that the discount rates appropriate to collateralised derivatives should be related to the funding cost arising from 
the collateral agreements. These represent the real borrowing or lending costs of each counterparty. The present value of the transaction should actually be calculated using a discount curve that reflects the funding paid on the collateral posted, rather than the generic Libor/Euribor rate. Pricing and valuation via collateral discounting is not yet a consistent market standard; moves in the Libor/Euribor-OIS ${ }^{15}$ have highlighted the need to adjust discount rates.

The swap market has already moved to the dual/multi-curve approach, with the London Clearing House using OIS discounting for clearing swaps; other markets, including swaptions, caps/floors, exotics and equities, are still evolving in the same direction. From this perspective spread risk does not now depend on the moneyness of the swap; given the above, we can also observe that spread and OIS rate risks are close for par swaps; however, there is a significant difference between spread and OIS rate risks for out-of-the-money (OTM) and at-the-money (ATM) swaps. The single-curve approach neglects the risk that actually exists, while the multi-curve approach enables these risks to be estimated. Risk under the single-curve approach is mispriced. In the discounting of the cash flow of derivatives, it is important to understand what the appropriate discount rates for collateralised derivatives is. There appear to be different solutions:

- Use risk-free rate curve to discount the derivative's cash flow. This means that the counterparties enter into a derivative transaction but do not manage the counterparty risk (this approach is based on non-arbitrage theory and was developed in the 1970s);

- The counterparties do not collateralise and define the MtM derivatives using risky discount curves;

- The counterparties are compliant with the new regulatory framework and so are immunised to the counterparty risk. In this case the financial intermediaries define the MtM derivatives using a different discount curve (a double-multi-curve approach) related to the funding

\footnotetext{
${ }^{15}$ OIS (Overnight Index Swaps) are also swaps, where at maturity, one party will pay an amount based on a daily geometric accrual of an index and will receive the OIS rate for the period. The daily accrual rates for OIS are typically based on overnight central bank rates. In a EUR OIS, the daily accrual is based on Eonia, while for a GBP OIS it is Sonia.
} 
cost arising from the collateral agreements. These represent the real borrowing or lending costs of each counterparty.

In the double-multi-curve approach the curves used by financial intermediaries to estimate the interest payable do not coincide with those used when discounting them. In this approach the interest swap cash flows are defined from a set of yield curves based on the values expressed by the Euribor curve, which produces the respective curve rate term along with the bootstrapping procedure. The discount curve, however, is obtained through bootstrapping from a yield curve based on the values expressed by the Ois-Eonia curve. The adoption of this approach enables the remuneration of the collateral to be taken into account, as the amount of the guarantee is generally recalculated and adjusted on a daily basis, and therefore the interest rate used to finance this adjustment should be the overnight rate and not a money-market rate with a higher maturity.

The rationale behind this assumption is that in the interbank derivatives market, a collateral agreement (CSA) is often negotiated between two counterparties. The CSA is set to mitigate the credit risk of both parties, allowing them to establish bilateral mark-to-market collateral arrangements. We assume here that the collateral, typically a bond or cash, is revalued daily at a rate equal (or close) to the overnight rate, which can thus justify the use of OIS rates for discounting.

In this field, the pricing measures considered by Kijima et al. (2009), are those associated with the discount curve. This is also consistent with the results of Fujii et al. (2009) and Piterbarg (2010), since we assume CSA agreements where the collateral rate to be paid equals the (assumed risk-free) overnight rate.

The reason for the double-multi-curve approach to the evaluation of derivative products is to be found in the financial crisis and in the consequent regulatory framework that originated in the second half of 2007, which has produced - among other consequences - a review of the pricing methodologies of derivatives. In this market environment, the classic approach based on the assumption of the absence of arbitration-and thus the existence of a single risk-free yield curve with which to use and/or raise liquidity-has become outdated. The single-curve and multi-curve approaches can diverge substantially in pricing and risk calculations. 
The discount single-curve approach essentially ignores collateral management activated by the risk manager and spread risks together; the mispricing of risk seems to be significant when the spread increases.

\subsection{Aspects of Valuation in the Presence of Collateralisation Agreements}

The Ois-Eonia discounting valuation framework foresees the use of:

(1) A yield curve (called discounting curve) based on the values expressed by the Ois-Eonia curve, from which to obtain (by bootstrapping) the curve for a zero-maturity coupon to be used to discount the future cash flows of the derivative products;

(2) A set of different yield curves ${ }^{16}$ (called forward curves) based on the values expressed by the different Euribor curves (for example, Euribor $1 \mathrm{M}$, Euribor 3M, Euribor 6M, etc.), from which to derive (through the individual bootstrapping procedure) the respective curves for maturities of forward rates: ${ }^{17}$ these rates are used to value future cash

\footnotetext{
${ }^{16}$ The consideration of each yield curve for the determination of the mark to model of the single product is derived according to the maturity of the variable rate to which the derivative is indexed.

${ }^{17}$ From the application point of view, the new multicurve framework based on OIS discounting implies that the procedure to determine the OIS zero curve is similar to that used to determine the Euribor/swap zero curve in a discounting Euribor system, while the new technique concerns the method of determining the forwarding curves: namely the set of forward rate curves useful to enhance the cash flow of the derivatives whose tenor of reference rate is consistent with that of the quotations from which the derivatives are obtained.

In this regard and in brief, there are considered a number of swap prices relating to a set of interest rate swaps traded in the market, each having a notional amount equal to $\mathrm{N}$ and a different deadline.

Using the matrix representation, for each of the interest rate swap considered the value of the fixed part is obtained as:
}

$$
\left|\begin{array}{ccccc}
N c_{1}+N & 0 & 0 & \ldots & 0 \\
N c_{2} & N c_{2}+N & 0 & \ldots & 0 \\
N c_{3} & N c_{3} & N c_{3}+N & \ldots & 0 \\
\ldots & \ldots & \ldots & \ldots & \ldots \\
N c_{j} & N c_{j} & N c_{j}+N & \ldots & N c_{j}+N
\end{array}\right|
$$


flows of derivatives. It goes without saying that the individual bootstrapping procedures must be calibrated in such a way as to be consistent with the structure of zero-coupon yield derived from the procedure referred to in point 1 and in order to reproduce a result consistent with the market values observed.

A consequence of the financial crisis was the presence of significantly different spread from zero in the market of the swap basis (for example, Euribor $6 \mathrm{M}$ against Euribor $3 \mathrm{M}$ ) on account. The reason for a significant counterparty risk which-if not mitigated-is higher, is the frequency of the payments associated with a particular financial instrument. Consequently the IRS rate quotes against Euribor in the short term (for example, Euribor $3 \mathrm{M}$ ) have become lower than the IRS rates against Euribor with a longer maturity (for example, Euribor 6M). The emergence of this significant counterparty risk has necessitated the adoption of mitigation techniques: specifically the presence of derivative transactions guaranteed by collateral — to mitigate the risk profile mentionedhas become the best market practice. This technique, which involves the valuation of derivative instruments, must take into account the mode of remuneration of the collateral itself.

Since the amount of collateral given as a guarantee depends on the amount of mark to model of the derivative products, typically recalculated on a daily basis, this must be suitable for the same frequency. This implies that the interest rate used to finance the adjustment of the daily collateral

where the generic discount factor $v j$ is valued on the basis of a zero coupon $j$-esimo obtained from the OIS zero curve. As is known, at the time of negotiation of each interest rate swap the value of the fixed part must be equal to that of the variable part for which we have:

$$
\left|\begin{array}{ccccc}
N v_{1} & 0 & 0 & \ldots & 0 \\
N v_{1} & N v_{2} & 0 & \ldots & 0 \\
N v_{1} & N v_{2} & N v_{3} & \ldots & 0 \\
\ldots & \ldots & \ldots & \ldots & 0 \\
N v_{1} & N v_{2} & N v_{3} & \ldots & N v_{j}
\end{array}\right| \times\left|\begin{array}{c}
a_{1} \\
a \\
a_{3} \\
\ldots \\
a_{j}
\end{array}\right|=\left|\begin{array}{c}
P_{1}-N v_{1} \\
P_{2}-N v_{2} \\
P_{3}-N v_{3} \\
\ldots \\
P_{j}-N v_{j}
\end{array}\right|
$$

where the generic term $a j$ represents the forward rate necessary to enhance the $\mathrm{j}$-esimo cash flow of the variable part of the swap, determined by solving the j-esime relations that tie the value of the variable part to that of the fixed part of the interest rate swaps traded on the market. 
must be the overnight rate rather than a market money rate with a higher maturity like Euribor. Consequently, the cost of the position must be expressed as the expected value of future cash-flow discounted derivatives with a curve formed not more than the IRS quotes against Euribor (as would previously have been the case) but those relating to the OIS. This implies that the curve used for the estimation of interest payable is no longer equal to that used for the discounting. In formal terms, let $V(t)$ be the value, where $t$ is the time, of a collateralised derivative instrument; at that specific point in time the amount of collateral transferred $C(t)$ must approximately equal the mark to model of the same, namely:

$$
V(t) \cong C(t)
$$

This must also apply to the next general point in time $t+\Delta \mathrm{t}$ namely:

$$
V(t+d t) \cong C(t+d t)
$$

Keeping in mind that the amount of collateral at time $t+d t$ is equal to collateral at time $t$ capitalised at the Eonia rate for the time interval $d t$, we have:

$$
V(t+d t)-C(t) \times[1+r t] \cong 0
$$

which allows one to define the new formulation of the valuation process at time $t$ of the derivative instrument with maturity in $\mathrm{T}$ that in a regime of continuous discount is summarised as:

$$
V(t)=E\left[e^{-\int t^{T} r(s) d s} V_{T}\right] \underset{\text { if cash Euro }}{\Rightarrow} E\left[e^{-\int t^{T} \text { eonia }(s) d s} V_{T}\right]
$$

or the expected value of a derivative is collateralised by discounting the estimated value at maturity with the interest rate of the collateral. Being typically awarded in the form of cash collateral, the rate of return is equal 
to the overnight rate of currency (Eonia in the case of the euro), where OIS discounting in the valuation of the derivatives.

Now consider a case where the collateral is paid in the form of a bond; the quantity that is always paid on a daily basis and will vary during the entire life cycle of the contract. It is assumed that bank $\mathrm{X}$ has a negative $\mathrm{MtM}$, and must therefore post collateral. It is also assumed that the bank does not use bonds in this portfolio, but makes use of a type of contract repo (also collateralised) where money is taken and receives title to the collateral of the loan. In this way the bond may be "re-used"; this process is shown schematically in Fig. 4.1. Placing ourselves at the time $t+1$, assuming that the transaction is closed, bank $\mathrm{X}$ receives the bond collateral in place and, reversing the repo transaction, delivers the bond and receives the value of the loan plus the interest, accrued at the repo rate. The repo rate may be summarised as the Eonia rate plus a $\operatorname{spread} x$,

$$
\operatorname{repo}(t)=\text { eonia }+x
$$

Because of the loan plus the interest accrued at the Eonia rate, the spread $x$, representing the profit (or loss) generated by the bank during the operation, is returned to the money market. The repo rate is therefore the rate of return on collateral, for which the expected value of a fully collateralised derivative will be equal to:

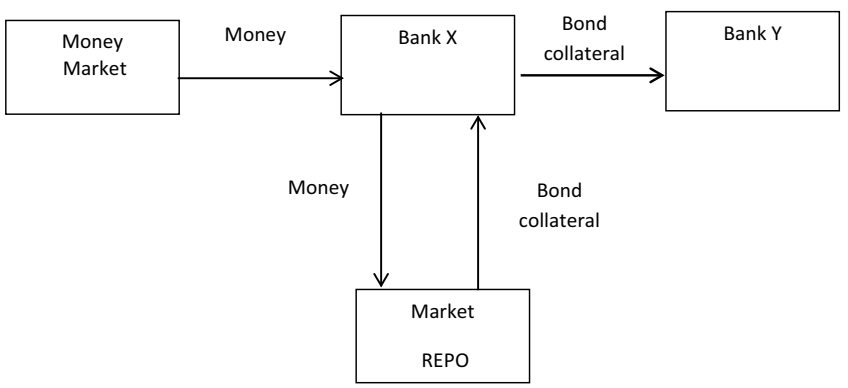

Fig. 4.1 Collateral agreement at time $t$ : Bank $X$ post collateral (Source: Author's elaboration) 


$$
V(t)=E\left[e^{-\int_{t}^{T} \operatorname{repo}(s) d s} \cdot V_{T}\right]:=E\left[e^{-\int_{t}^{T}(\text { eonia }(s)+x) d s} \cdot V_{T}\right]
$$

Only if $x$ is close to zero, is the process of collateralisation with the bond the same as with, which can still be used for the OIS discounting process in assessing the derivative instruments.

It goes without saying that the absence of collateralisation agreements requires the inclusion in the evaluation of derivatives in the component linked to the credit risk profile. Specifically, in the calculation of fair value it is estimated respectively that:

(1) The positive fair value of a derivative is adjusted by a factor of fair value that takes into account the fair value of the counterparty risk (called CVA);

(2) The negative fair value of a derivative is adjusted by a factor of fair value referring to its own credit risk (called DVA).

The above-mentioned adjustments must be applied in the valuations of the derivative products obtained with the multi-curves valuation framework based on the Eonia discounting used for the valuation of the derivative products collateralised.

\subsection{The Multi-curves Valuation Framework Based on Eonia Discounting: A Case Study}

The use of the multi-curves valuation frameworks based on Eonia discounting implies a change in the pricing and risk measurement processes in interest rate derivatives compared to the multi-curve based on Euribor discounting. Such processes are no longer the function of a single yield curve but of two yield curves, from which we obtain discounting curves and forwarding curves (linked to the former).

In fact, the forwarding curve is obtained first imposing the condition that the value of the fixed-rate interest flows discounted using the zero- 
coupon yield curve obtained from boostrapping-Eonia OIS must equal the value of the cash flows discounted variable rate, and also using the aforementioned zero-coupon rate. Applied recursively this condition assesses-in turn-forward rates that ensure compliance with the equal initial swap requirement. Therefore, the forward rates calculated using Eonia-OIS discounting are different from those calculated using Euribor discounting.

In this context, consider the rates-of-return curve represented by the Eonia-OIS rates on 11 February 2015 (when the market was characterised by the presence of negative interest rates) ${ }^{18}$ (Table 4.3).

From this curve we obtain, using a bootstrapping method, the following structure of zero-coupon rate to be used for discounting the cash flows of the collateralised derivative instruments (Table 4.4).

We then we consider the subsequent swap-rate curve in relation to Euribor $6 \mathrm{~m}^{19}$ (Table 4.5).

The forward rate structure that we obtain from this curve is shown in Table 4.6.

To understand the dynamics of defining the forward rates shown in Table 4.6, consider, for example, the forward rate for the period from $04 / 05 / 2020$ to $11 / 4 / 2020$.

The definition of implicit rate must be such as to ensure consistency with the plain vanilla interest rate swap 5 years traded in the market with the following characteristics:

Trade date $=11 / 2 / 15$

Start date $=11 / 4 / 15$

End date $=11 / 5 / 20$

5 years' fixed rate $=0.2875 \%$

Floating rate $=6$ months Euribor

In fact, as is known, the initial parity of interest rate swap constraint requires equality of the net present value of the fixed and floating legs. w

\footnotetext{
${ }^{18}$ The presence of negative interest rates also requires a shift in pricing interest rate options from a valuation framework type lognormal (Black model) to a framework normal (Bachelier model); the Black model assigns probabilities equal to zero to the fact that interest rates can take zero or negative values.

${ }^{19}$ The structure of the curve is composed of three segments: the first refers to the money market quotations, the second to FRA market and the last to interest-rate swaps against Euribor.
} 
Table 4.3 OIS vs Eonia curve

\begin{tabular}{|c|c|}
\hline Date & Rate \\
\hline $1 \mathrm{D}$ & -0.2 \\
\hline 2D & -0.205 \\
\hline $1 \mathrm{~W}$ & -0.142 \\
\hline $1 \mathrm{M}$ & -0.144 \\
\hline $2 \mathrm{M}$ & -0.171 \\
\hline $3 \mathrm{M}$ & -0.185 \\
\hline $4 \mathrm{M}$ & -0.196 \\
\hline $5 \mathrm{M}$ & -0.2067 \\
\hline $6 \mathrm{M}$ & -0.212 \\
\hline 7M & -0.216 \\
\hline $8 \mathrm{M}$ & -0.2249 \\
\hline $9 \mathrm{M}$ & -0.2292 \\
\hline $10 \mathrm{M}$ & -0.2332 \\
\hline $11 \mathrm{M}$ & -0.2361 \\
\hline $1 Y$ & -0.238 \\
\hline $2 Y$ & -0.2339 \\
\hline $3 Y$ & -0.184 \\
\hline $4 Y$ & -0.082 \\
\hline $5 Y$ & 0.036 \\
\hline $6 \mathrm{Y}$ & 0.169 \\
\hline $7 Y$ & 0.306 \\
\hline $8 Y$ & 0.442 \\
\hline $9 Y$ & 0.568 \\
\hline $10 Y$ & 0.681 \\
\hline $12 Y$ & 0.871 \\
\hline $15 Y$ & 1.08 \\
\hline $20 Y$ & 1.272 \\
\hline $25 Y$ & 1.334 \\
\hline $30 Y$ & 1.361 \\
\hline
\end{tabular}

wis illustrated in the specific cases reported respectively in Tables 4.7 and 4.8. In this regard, note that:

(1) to discount both sequences of interest rate swap cash flows, we use a zero-coupon interest rate structure (see "zero rates" column of Tables 4.7 and 4.8) obtained by the curve of Eonia-OIS rates;

(2) in this specific case, the forward rate ranging from 05/04/2020 to $11 / 04 / 2020$ equal to $0.82751 \%$ (for the last cash flow of the interest rate swap floating leg) is that which ensures the constraint of initial parity of the interest rate at 5 years listed in the market, whose fixed 
Table 4.4 Zero-coupon rate

\begin{tabular}{lll}
\hline Date & Days & Zero-coupon rate \\
\hline $3 / 11 / 2015$ & 1 & -0.20278 \\
$4 / 11 / 2015$ & 2 & -0.20531 \\
$11 / 11 / 2015$ & 9 & -0.15761 \\
$18 / 11 / 2015$ & 16 & -0.15253 \\
$25 / 11 / 2015$ & 23 & -0.15024 \\
$4 / 12 / 2015$ & 32 & -0.14972 \\
$4 / 1 / 2016$ & 63 & -0.17441 \\
$4 / 2 / 2016$ & 94 & -0.18799 \\
$4 / 3 / 2016$ & 123 & -0.19889 \\
$4 / 4 / 2016$ & 154 & -0.20961 \\
$4 / 5 / 2016$ & 184 & -0.21495 \\
$6 / 6 / 2016$ & 217 & -0.21901 \\
$4 / 7 / 2016$ & 245 & -0.22801 \\
$4 / 8 / 2016$ & 276 & -0.23239 \\
$5 / 9 / 2016$ & 308 & -0.23647 \\
$4 / 10 / 2016$ & 337 & -0.23944 \\
$4 / 11 / 2016$ & 368 & -0.2414 \\
$6 / 11 / 2017$ & 735 & -0.23735 \\
$5 / 11 / 2018$ & 1099 & -0.18686 \\
$4 / 11 / 2019$ & 1463 & -0.0835 \\
$4 / 11 / 2020$ & 1829 & 0.03637 \\
$4 / 11 / 2021$ & 2194 & 0.17201 \\
$4 / 11 / 2022$ & 2559 & 0.31247 \\
$6 / 11 / 2023$ & 2926 & 0.45283 \\
$4 / 11 / 2024$ & 3290 & 0.58383 \\
$4 / 11 / 2025$ & 3655 & 0.7022 \\
$4 / 11 / 2026$ & 4020 & 0.80847 \\
$4 / 11 / 2027$ & 4385 & 0.9034 \\
$6 / 11 / 2028$ & 4753 & 0.98808 \\
$5 / 11 / 2029$ & 5117 & 1.06278 \\
$4 / 11 / 2030$ & 5481 & 1.12838 \\
$4 / 11 / 2031$ & 5846 & 1.1855 \\
$4 / 11 / 2032$ & 6212 & 1.23469 \\
$4 / 11 / 2033$ & 6577 & 1.27606 \\
$6 / 11 / 2034$ & 6944 & 1.31014 \\
$5 / 11 / 2035$ & 7308 & 1.3374 \\
$4 / 11 / 2036$ & 7673 & 1.35839 \\
$4 / 11 / 2037$ & 8038 & 1.37399 \\
$4 / 11 / 2038$ & 8403 & 1.38539 \\
$4 / 11 / 2039$ & 8768 & 1.39373 \\
$5 / 11 / 2040$ & 9135 & 1.40019 \\
$4 / 11 / 2041$ & 9499 & 1.40579 \\
$4 / 11 / 2042$ & 9864 & 1.41085 \\
$4 / 11 / 2043$ & 10229 & 1.41554 \\
$4 / 11 / 2044$ & 10595 & 1.42002 \\
$6 / 11 / 2045$ & 10962 & 1.42444 \\
\hline $504 / c e: A 4 t h 6 r 5$ & 501 \\
\hline
\end{tabular}

Source: Author's elaboration 
Table 4.5 Swap curve vs Euribor $6 \mathrm{~m}$

\begin{tabular}{lll}
\hline Date & & Rate \\
\hline $1 \mathrm{D}$ & & -0.2 \\
2D & & -0.205 \\
$6 \mathrm{M}$ & & 0.006 \\
Start & End & Rate \\
$1 \mathrm{M}$ & $7 \mathrm{M}$ & -0.017 \\
$2 \mathrm{M}$ & $8 \mathrm{M}$ & -0.035 \\
$3 \mathrm{M}$ & $9 \mathrm{M}$ & -0.042 \\
$4 \mathrm{M}$ & $10 \mathrm{M}$ & -0.048 \\
$5 \mathrm{M}$ & $11 \mathrm{M}$ & -0.053 \\
$6 \mathrm{M}$ & $12 \mathrm{M}$ & -0.056 \\
$9 \mathrm{M}$ & $15 \mathrm{M}$ & -0.053 \\
$12 \mathrm{M}$ & $18 \mathrm{M}$ & -0.037 \\
$18 \mathrm{M}$ & $24 \mathrm{M}$ & 0.024 \\
$2 \mathrm{Y}$ & & -0.016 \\
$3 \mathrm{Y}$ & & 0.0516 \\
$4 \mathrm{Y}$ & & 0.1649 \\
$5 \mathrm{Y}$ & & 0.2875 \\
$6 \mathrm{Y}$ & & 0.421 \\
$7 \mathrm{Y}$ & & 0.559 \\
$8 \mathrm{Y}$ & & 0.691 \\
$9 \mathrm{Y}$ & & 0.814 \\
$10 \mathrm{Y}$ & & 0.92 \\
$12 \mathrm{Y}$ & & 1.104 \\
$15 \mathrm{Y}$ & & 1.294 \\
$20 \mathrm{Y}$ & & 1.46 \\
$25 \mathrm{Y}$ & & 1.502 \\
$30 \mathrm{Y}$ & & 1.52 \\
$50 \mathrm{Y}$ & & 1.485 \\
\hline $50 u r c e$ & & \\
& &
\end{tabular}

Source: Author's elaboration

rate is $0.2875 \%$. In other words, given that the net present value of fixed-rate interest amounts to -1.441 .643 , the forward rate above is what allows the ultimate interests of the sequence flow of the cash floating rate to be enhanced, the present total value of which is equal to 1.441 .643 (the forward rates which are enhanced flows of floating interest rates earlier than the present one are obtained as described in the specific case examined).

Even the results of the quantitative risk analysis are-in this contextthe result of derivative contracts' sensitivity to two yield curves. 
4 OTC Derivatives and Counterparty Credit Risk Mitigation:...

Table 4.6 Forward rate curve

\begin{tabular}{lll}
\hline Date & Days & Forward rates \\
\hline $4 / 11 / 2015$ & 2 & 0.006 \\
$4 / 5 / 2016$ & 184 & -0.056 \\
$4 / 11 / 2016$ & 368 & -0.037 \\
$4 / 5 / 2017$ & 549 & 0.02335 \\
$6 / 11 / 2017$ & 735 & 0.1512 \\
$4 / 5 / 2018$ & 914 & 0.21717 \\
$5 / 11 / 2018$ & 1099 & 0.44293 \\
$6 / 5 / 2019$ & 1281 & 0.5553 \\
$4 / 11 / 2019$ & 1463 & 0.70576 \\
$4 / 5 / 2020$ & 1645 & 0.82751 \\
$4 / 11 / 2020$ & 1829 & 1.01299 \\
$4 / 5 / 2021$ & 2010 & 1.14595 \\
$4 / 11 / 2021$ & 2194 & 1.31285 \\
$4 / 5 / 2022$ & 2375 & 1.45126 \\
$4 / 11 / 2022$ & 2559 & 1.54558 \\
$4 / 5 / 2023$ & 2740 & 1.67912 \\
$6 / 11 / 2023$ & 2926 & 1.74986 \\
$6 / 5 / 2024$ & 3108 & 1.87567 \\
$4 / 11 / 2024$ & 3290 & 1.84282 \\
$5 / 5 / 2025$ & 3472 & 1.95029 \\
$4 / 11 / 2025$ & 3655 & 1.97003 \\
$4 / 5 / 2026$ & 3836 & 2.07008 \\
$4 / 11 / 2026$ & 4020 & 2.06099 \\
$4 / 5 / 2027$ & 4201 & 2.15206 \\
$4 / 11 / 2027$ & 4385 & 2.07139 \\
$4 / 5 / 2028$ & 4567 & 2.14945 \\
$6 / 11 / 2028$ & 4753 & 2.07755 \\
$4 / 5 / 2029$ & 4932 & 2.14314 \\
$5 / 11 / 2029$ & 5117 & 2.07146 \\
$6 / 5 / 2030$ & 5299 & 2.12835 \\
$4 / 11 / 2030$ & 5481 & 2.06739 \\
$5 / 5 / 2031$ & 5663 & 2.11537 \\
$4 / 11 / 2031$ & 5846 & 2.04678 \\
$4 / 5 / 2032$ & 6028 & 2.08822 \\
$4 / 11 / 2032$ & 6212 & 2.01405 \\
$4 / 5 / 2033$ & 6393 & 2.04944 \\
$4 / 11 / 2033$ & 6577 & 1.95652 \\
$4 / 5 / 2034$ & 6758 & 1.98524 \\
$6 / 11 / 2034$ & 6944 & 1.88857 \\
$4 / 5 / 2035$ & 7123 & 1.91037 \\
$5 / 11 / 2035$ & 7308 & 1.7986 \\
$5 / 5 / 2036$ & 7490 & 1.8141 \\
$4 / 11 / 2036$ & 7673 & 1.72108 \\
$4 / 5 / 2037$ & 7854 & 1.73093 \\
& & \\
\hline
\end{tabular}


Table 4.6 (continued)

\begin{tabular}{lll}
\hline Date & Days & Forward rates \\
\hline $4 / 11 / 2037$ & 8038 & 1.65487 \\
$4 / 5 / 2038$ & 8219 & 1.66146 \\
$4 / 11 / 2038$ & 8403 & 1.60969 \\
$4 / 5 / 2039$ & 8584 & 1.6138 \\
$4 / 11 / 2039$ & 8768 & 1.58718 \\
$4 / 5 / 2040$ & 8950 & 1.59005 \\
$5 / 11 / 2040$ & 9135 & 1.59962 \\
\hline
\end{tabular}

Source: Author's elaboration

\section{Determination of Capital Requirement when Credit Risk Mitigation Techniques are Adopted: Case Study}

The effective management of credit risk mitigation techniques in terms of reducing financial exposure in derivatives transactions and foreign exchange contracts is recognised in the form of the lower capital charges required both for the counterparty risk and for the risk adjustment of the valuation for the credit risk, called CVA. Consider the example portfolio of derivatives and foreign exchange contracts shown in Table 4.9.

Using the financial evidence that was included in Table 4.3 in relation to this portfolio gives us the situation shown in Table 4.10.

Let us consider the case of a bank which applies the market value method-referred to in Article 274 of CRR — to determine the capital requirement for counterparty risk and to measure the different capital absorption required under three different assumptions:

(a) Absence of credit risk mitigation agreements;

(b) Presence only of compensation agreements in respect of the mark to market of the insurance portfolio;

(c) Presence both of compensation agreements and of collateralisation agreements.

In reference to point (c) with regards to we also assume consideration of the two different regulatory methods of financial collateral:

(c1) the simplified method referred to in Article 222 of the CRR; 


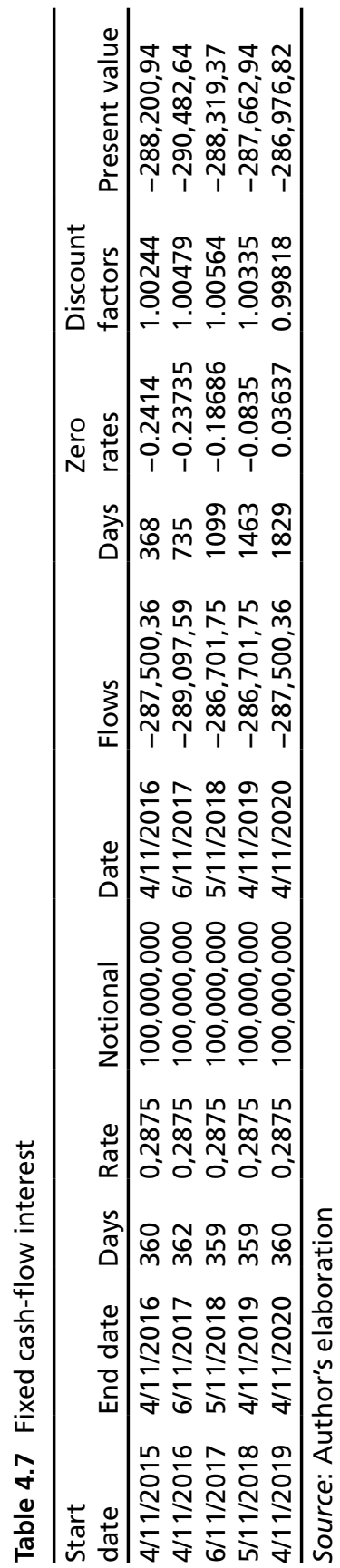




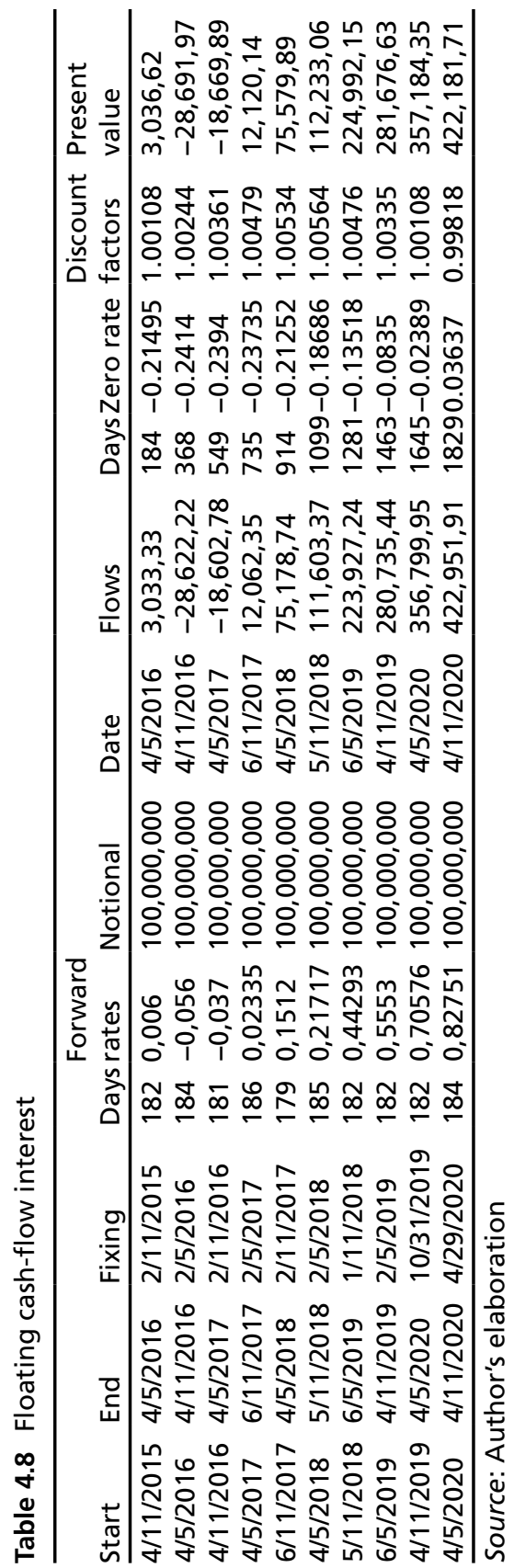


Table 4.9 Hypothetical portfolio derivatives and foreign exchange contracts

\begin{tabular}{llllll}
\hline & & & & Add & \\
& Remaining & & & on \\
Type of & term of each & Notional & Mark to & factor & Exposure at \\
trade & contract & amount & market & $\%$ & default \\
\hline IRS & 1,19 & $3,000,000$ & 126,100 & 0.50 & 15,000 \\
IRS & 1,19 & $3,000,000$ & 125,625 & 0.50 & 15,000 \\
IRS & 1,19 & $3,000,000$ & 125,245 & 0.50 & 15,000 \\
IRS & 1,19 & $4,000,000$ & 167,500 & 0.50 & 20,000 \\
IRS & 0,03 & $3,000,000$ & 48,501 & 0.00 & 0 \\
IRS & 0,03 & $5,000,000$ & 80,248 & 0.00 & 0 \\
IRS & 0,03 & $3,000,000$ & 49,747 & 0.00 & 0 \\
IRS & 0,03 & $2,000,000$ & 33,300 & 0.00 & 0 \\
IRS & 1,73 & $3,000,000$ & 205,304 & 0.50 & 15,000 \\
IRS & 1,73 & $3,000,000$ & 210,823 & 0.50 & 15,000 \\
IRS & 1,73 & $3,000,000$ & 218,416 & 0.50 & 15,000 \\
IRS & 2,26 & $3,000,000$ & 380,711 & 0.50 & 15,000 \\
IRS & 2,26 & $3,000,000$ & 385,543 & 0.50 & 15,000 \\
IRS & 1,73 & $2,000,000$ & 143,568 & 0.50 & 10,000 \\
IRS & 2,26 & $3,000,000$ & 386,076 & 0.50 & 15,000 \\
IRS & 2,26 & $4,000,000$ & 515,478 & 0.50 & 20,000 \\
IRS & 1,73 & $2,000,000$ & 150,317 & 0.50 & 10,000 \\
IRS & 1,79 & $3,000,000$ & 240,535 & 0.50 & 15,000 \\
IRS & 2,38 & $4,000,000$ & 527,901 & 0.50 & 20,000 \\
IRS & 1,79 & $3,000,000$ & 237,705 & 0.50 & 15,000 \\
IRS & 2,38 & $4,000,000$ & $-523,242$ & 0.50 & 20,000 \\
IRS & 2,38 & $2,000,000$ & 259,659 & 0.50 & 10,000 \\
IRS & 1,79 & $2,000,000$ & 156,247 & 0.50 & 10,000 \\
IRS & 1,79 & $3,000,000$ & 221,903 & 0.50 & 15,000 \\
IRS & 2,38 & $3,000,000$ & 378,455 & 0.50 & 15,000 \\
IRS & 1,79 & $2,000,000$ & 148,963 & 0.50 & 10,000 \\
IRS & 0,40 & $3,000,000$ & 52,752 & 0.00 & 0 \\
IRS & 0,40 & $3,000,000$ & 51,758 & 0.00 & 0 \\
IRS & 0,40 & $2,804,000$ & 50,060 & 0.00 & 0 \\
IRS & 3,26 & $7,000,000$ & 182,756 & 0.50 & 35,000 \\
IRS & 6,85 & $3,000,000$ & 93,354 & 1.50 & 45,000 \\
Outright & 0,04 & 8,951 & -293 & 1.00 & 90 \\
Outright & 0,33 & 82,279 & 7,600 & 1.00 & 823 \\
Outright & 0,38 & 82,261 & $-5,675$ & 1.00 & 823 \\
Outright & 0,30 & 82,287 & 5,165 & 1.00 & 823 \\
Outright & 0,38 & 164,523 & 10,523 & 1.00 & 1,645 \\
Outright & 0,02 & 72,890 & 2,906 & 1.00 & 729 \\
Outright & 0,35 & 82,272 & 2,694 & 1.00 & 823 \\
Outright & 0,50 & 123,334 & 3,425 & 1.00 & 1,233 \\
\hline & & & & & $($ continued) \\
& & & & &
\end{tabular}


Table 4.9 (continued)

\begin{tabular}{llllll}
\hline & $\begin{array}{l}\text { Remaining } \\
\text { Type of } \\
\text { term of each }\end{array}$ & $\begin{array}{l}\text { Notional } \\
\text { trade }\end{array}$ & $\begin{array}{l}\text { Mark to } \\
\text { contract }\end{array}$ & $\begin{array}{l}\text { Add } \\
\text { on } \\
\text { factor } \\
\%\end{array}$ & $\begin{array}{l}\text { Exposure at } \\
\text { default }\end{array}$ \\
\hline Cap & 0,34 & $8,100,000$ & 75,646 & 0.00 & 0 \\
IRS & 0,34 & $9,000,000$ & 83 & 0.00 & 0 \\
Cap & 0,07 & $8,100,000$ & 68,119 & 0.00 & 0 \\
IRS & 0,07 & $9,000,000$ & 12,355 & 0.00 & 0 \\
\hline
\end{tabular}

Source: Author's elaboration

Table 4.10 MtM of the portfolio

\begin{tabular}{ll}
\hline $\begin{array}{l}\text { Value of contracts having a positive mark to } \\
\text { market }\end{array}$ & $6,143,067$ \\
$\begin{array}{l}\text { Value of contracts having a negative mark to } \\
\text { market }\end{array}$ & $-529,210$ \\
Mark to market net of contracts & $5,613,857$ \\
\hline
\end{tabular}

Source: Author's elaboration

(c2) the integral method referred to in Articles 223-232 of the CRR.

Table 4.11 represents the relative outcomes in terms of capital charges required where the guarantee exchanged daily by the bank is represented by securities issued by the Central Administration eligible for a risk weight of $0 \%$ risk.

Note that the combined presence of compensation and collateralisation agreements - significantly reducing the financial exposure-requires lower absorption of regulatory capital than in the absence of credit risk mitigation instruments. More specifically:

(1) the effectiveness of compensation agreements in terms of lower capital requirement is greater than when the net mark to market of the bank is close to zero, i.e., when the value of the derivative contracts and foreign exchange transactions are completed with only a positive mark to market it is balanced substantially against the value of such contracts with a negative mark to market;

(2) the effectiveness of the collateral agreements, however, is much greater in terms of lower capital requirement since the higher net 
Table 4.11 Simulation of capital requirement

\begin{tabular}{|c|c|c|}
\hline & $\begin{array}{l}\text { Simplified } \\
\text { method }\end{array}$ & $\begin{array}{l}\text { Integral } \\
\text { method }\end{array}$ \\
\hline Cost of gross replacement & $6,143,067$ & $6,143,067$ \\
\hline Cost of net replacement & $5,613,857$ & $5,613,857$ \\
\hline Gross future credit exposure & 411,988 & 411,988 \\
\hline $\begin{array}{l}\text { RNL ( = net replacement cost/gross replacement } \\
\text { cost) }\end{array}$ & 0,914 & 0,914 \\
\hline Net future credit exposure & 390,693 & 390,693 \\
\hline Credit equivalent calculated on a gross basis & $6,555,055$ & $6,555,055$ \\
\hline Credit equivalent calculated on a net basis & $6,004,550$ & $6,004,550$ \\
\hline Guarantees received & $4,480,000$ & $5,600,000$ \\
\hline Covered share exposure & $4,480,000$ & \\
\hline Not covered share exposure & $1,524,550$ & 404,550 \\
\hline $\begin{array}{l}\text { (a) Capital requirement (assuming there is no } \\
\text { credit risk mitigation agreement) }\end{array}$ & 524,404 & 524,404 \\
\hline $\begin{array}{l}\text { (b) Capital requirement (assuming the presence } \\
\text { only of compensation agreements) }\end{array}$ & 480,364 & 480,364 \\
\hline $\begin{array}{l}\text { (c) Capital absorption (assuming the presence of } \\
\text { compensation and collateralisation } \\
\text { agreements) }\end{array}$ & 121,964 & 32,364 \\
\hline
\end{tabular}

Source: Author's elaboration

mark-to-market position in derivatives and foreign exchange contracts: since the same apply to the net replacement cost. In other words the relative capital absorption is substantially determined by the component of equal credit represented by future credit exposure. From this point of view, however, the adoption of the market value method may be deemed disadvantageous, since the determination of future credit exposure takes place with a mechanical calculation where-depending on the type of derivative contract - the notional amounts of each of these are multiplied by weighting factors whose magnitude depends on the residual life of each contract. It follows that the risk in the calculation of future credit exposure is inconsistent with the actual risk profile resulting from the operational management of collateral which-assuming collateral is adapted on a daily basis-implies that the risk does not extend to the life of the contracts, but only to the time interval between the time when the MtM of contracts is detected and the time when the guarantees already available are integrated. 
Table 4.12 Synthesis of new financial characteristics of the portfolio

Value of contracts having a positive mark to market $3,749,675$

Value of contracts having a negative mark to market $-2,922,601$

Mark to market net of contracts 827,074

Source: Author's elaboration

Table 4.13 Simulation of the capital requirements based on the new evidence contained in Table 4.11

\begin{tabular}{|c|c|c|}
\hline & $\begin{array}{l}\text { Simplified } \\
\text { method }\end{array}$ & $\begin{array}{l}\text { Integral } \\
\text { method }\end{array}$ \\
\hline Mark to market & 827,074 & 827,074 \\
\hline Cost of gross replacement & $3,749,675$ & $3,749,675$ \\
\hline Cost of net replacement & 827,074 & 827,074 \\
\hline Gross future credit exposure & $411,988,0$ & $411,988,0$ \\
\hline $\begin{array}{l}\mathrm{RNL}(=\text { net replacement cost/gross } \\
\text { replacement cost) }\end{array}$ & 0,221 & 0,221 \\
\hline Net future credit exposure & 219,319 & 219,319 \\
\hline Credit equivalent calculated on a gross basis & $4,161,663,43$ & $4,161,663$ \\
\hline Credit equivalent calculated on a net basis & $1,046,393$ & $1,046,393$ \\
\hline Guarantees received & 640,000 & 800,000 \\
\hline Covered share exposure & 640,000 & \\
\hline Not covered share exposure & 406,393 & 246,393 \\
\hline $\begin{array}{l}\text { (a) Capital requirement (assuming that there } \\
\text { is no credit risk mitigation agreement) }\end{array}$ & 332,933 & 332,933 \\
\hline $\begin{array}{l}\text { (b) Capital requirement (assuming the } \\
\text { presence only of compensation } \\
\text { agreements) }\end{array}$ & 83,712 & 83,712 \\
\hline $\begin{array}{l}\text { (c) Capital requirement (assuming the } \\
\text { presence of compensation and } \\
\text { collateralisation agreements) }\end{array}$ & 32,512 & 19,712 \\
\hline
\end{tabular}

Source: Author's elaboration

To give substance to these two points, let us assume that the evidence of the financial portfolio seen earlier is instead the following (Table 4.12).

Table 4.13 represents the new outcomes in terms of capital charges required.

A comparison of the two financial situations relating to derivatives and foreign exchange contracts represented respectively in Tables (assuming that the bank adopts the simplified method) shows that: 
- in the first case, where the net MtM portfolio is 5,613,857, the compensation agreements are equivalent $11 \%$ of the overall reduction of the capital, while the collateralisation agreements equal $89 \%$;

- in the second case, where the net MtM of the portfolio is 827,074 , the compensation agreements are equivalent to $83 \%$ of the overall reduction of the capital, while the collateralisation agreements equal $17 \%$.

Furthermore it is clear that adopting-for the treatment of financial collateral - the integral method rather than the simplified one makes it possible to take advantage of a greater reduction in the absorption of capital. This is because under the simplified method when the guarantee is represented by securities issued by central governments eligible for a risk weighting of $0 \%$, Article 222 paragraph 6(a) of the CRR anticipates-by way of prudence-the application of a $20 \%$ discount to the market value of the collateral.

The more favourable prudential treatment in the case of the adoption of credit risk mitigation can be appreciated by considering the additional capital required by the CRR on activities in derivatives and foreign exchange contracts in order to cover the risk for the credit valuation adjustment (CVA). Applying the standard method in Article 384 to the situation referred to in Table 4.10 gives the capital requirements shown in Table 4.13 .

\section{Some Conclusions}

The move from traditional Libor to OIS discounting involves a newfound appreciation of counterparty credit risk and the role of collateral and central clearing. In this chapter we illustrate the market trends and the subsequent regulatory framework that, from 2009 onwards, led market participants: (a) to increase the use of central counterparties (CCPs), which requires daily collateral maintenance, and (b) adopt the overnight index swap (OIS) as the "new risk-free swap curve". Nowadays pricing and valuation via collateral discounting is not yet a consistent market standard; many financial institutions are currently in the process of migrating to the new evaluation framework, but questions remain as to 
the potential impact on existing portfolios and how to effectively manage instruments with longer-dated maturities when spreads in Libor begin to diverge from OIS rates. Differential discounting refers to the practice of valuing a derivative contract (e.g., a credit default swap (CDS)) using discount rates that are specified in the terms of collateral agreements between the counterparties; OIS discounting means discounting the expected cash flows of a derivative using a nearly risk-free curve such as an OIS curve.

The single-curve approach essentially ignores collateral and spread risks together; the mispricing of risk is significant when the spread increases. Consistent valuation techniques are critical, both throughout a firm and relative to the market, with front, middle and back office computational consistency essential. Without this consistency, market quotes and counterparty valuations will diverge, risk calculations will differ between departments, and correct hedging decisions will be compromised. Given the movement towards standardisation, the interest rate pricing framework needs to be carefully reviewed from its very foundation. Fortunately for risk managers, OIS discounting uses the same types of analytical techniques as the traditional discounting approach of bootstrapping. However, there are some differences, for instance, calculating the sensitivities of swap values to changes in OIS rates and the Libor/ Euribor-OIS spread (i.e. working with dual curves rather than a single curve for risk measurement) and dealing with cross-currency swaps. Also, Libor/Euribor are interest rates that can reasonably be assumed to vary daily in the interbank market whereas the OIS rate is more directly a tool of monetary policy, and so its volatility rate depends on the pattern and timing of policy meetings and actions. As it is typical to post cash collateral, the market standard is to use discount rates that reflect the yield paid on the cash collateral posted. The market convention is to pay a rate based on overnight lending, rather than Libor which typically has a three-month term.

The collateralisation of the counterparty risk not only implies that the $\mathrm{MtM}$ on derivatives takes into account the remuneration of the collateral itself through the application of appropriate discount curves but also has an impact on capital requirements for financial intermediaries, as our 
case study showed. Furthermore it is clear that if - the integral method instead of the simplified one is adopted for the treatment of financial collateral, it is possible to take advantage of a greater reduction in the absorption of capital. The case study shows that the combined presence of compensation and collateralisation agreements_-significantly reducing financial exposure-requires a lower regulatory capital absorption than is the case in the absence of credit risk mitigation instruments. All this underlines the strategic role of the counterparty risk management function in financial intermediaries in light of the scarcity of capital in the actual market context.

\section{References}

BCBS. (2011). International regulatory framework for banks, http://www.bis. org/bcbs/basel3.htm

Fujii, M., Shimada, Y., \& Takahaschi, A. (2009). A note on construction of multiple swap curves whit and without collateral, CARF Working Paper Series.

Kijima, M., Suzuki, T. \& Tanaka, K. (2009). A latent process model for the pricing of corporate securities, Mathematical Methods of Operations Research, 69, 439-455.

Piterbarg, V. (2010). Funding beyond discounting: Collateral agreements and derivatives pricing, Risk. February.

Porretta, P., Proietti, M., \& Germini, F. (2011). The counterparty risk: View of vigilance and management aspects, Bancaria, No. 1. 